\title{
Genetic Similarity Theory: Beyond Kin Selection
}

\author{
J. Philippe Rushton, ${ }^{1,3}$ Robin J. H. Russell, ${ }^{2}$ and Pamela A. Wells ${ }^{2}$
}

Received 24 Dec. 1983-Final 23 Mar. 1984

We present genetic similarity theory (GST), which incorporates the kinselection theory of altruism under a more general principle. GST states that a gene ensures its own survival by acting so as to bring about the reproduction of any organism in which copies of itself are to be found. Rather than behaving altruistically only toward kin, organisms are able to detect other genetically similar organisms and to exhibit favoritism and protective behavior toward these "strangers," as well as toward their own relatives. In order to pursue this general strategy, an organism must, in effect, be able to detect copies of its genes in other organisms. We order several data sets with this theory including (a) kin recognition studies in animals raised apart, (b) assortative mating, (c) intrafamilial relations, (d) human friendship and altruism, and (e) ethnic nepotism. We discuss a strong and a weak version of GST and offer some predictions for future research.

KEY WORDS: altruism; assortative mating; friendship, genetic similarity theory; inclusive fitness; kin recognition; kin-selection theory; personality; sociobiology.

\section{INTRODUCTION}

In this article we propose genetic similarity detection as a mechanism by which organisms are attracted and repelled by each other. We hypothesize that genetically similar others ("strangers," as well as "kin") have a tendency to seek each other out and provide mutually supportive environments, while genetically dissimilar others have a tendency to form

\footnotetext{
'Department of Psychology, University of Western Ontario, London, Ontario, Canada N6A 5C2.

${ }^{2}$ Department of Psychology, University of London Goldsmiths' College, London, England SE14 6NW.

3 To whom correspondence should be addressed.
} 
natural antipathies and provide mutually hostile environments. By responding differentially to the degree of genetic similarity in others, organisms help increase the frequency of their genes in the next generation. We explicate this theory in the context of altruism and thereby incorporate the kin-selection theory of altruism under a more general principle.

\section{RESOLVING THE PARADOX OF ALTRUISM}

The study of altruism has burgeoned in recent years. Analyses have been provided from a multiplicity of disciplines as wide ranging as anthropology, economics, ethical philosophy, sociology, and, of course, social, personality, and developmental psychology (Rushton and Sorrentino, 1981). One reason for this increasing interest is the realization that the existence of altruism poses a central dilemma for all theories attempting to account for human nature. For most social scientists, the focus on altruism has been in terms of socialization. It is now widely known, however, that altruism has its roots deep in evolutionary history and is to be found in many animal species (Wilson, 1975). Moreover, using the classical twin method, individual differences in human altruism have been found to be about $50 \%$ heritable (Rushton et al., 1984).

Altruism is typically defined by sociobiologists as "self-destructive behavior performed for the benefit of others" (Wilson, 1975, p. 578). In this paper the concept is used more widely to include less extreme behaviors which also have the effect of benefiting others rather than the self. A genetic basis to altruism, however, poses a paradox for theories of evolution. How could altruism evolve through Darwin's hypothesized "survival of the fittest individual" when such behavior would appear to diminish personal fitness? If the most altruistic members of a group sacrificed themselves for others, they ran the risk of leaving fewer offspring to carry forward their genes for altruistic behavior. Hence altruism would be selected out, and indeed, selfishness would be selected in. Many naturalistic studies, however, have demonstrated that altruistic behaviors are pervasive in animal species as disparate as social insects, birds, rabbits, deer, elephants, porpoises, and chimpanzees (Wilson, 1975). Some species are altruistic to the point of self-sacrifice. For example, honey bees die when they sting in the process of protecting their nests. How could such behavior possibly evolve through Darwinian selection?

The solution to the paradox of altruism is one of the triumphs that led to the new synthesis of sociobiology. The answer proposed was that individuals behave so as to maximize their inclusive fitness rather than only their individual fitness by increasing the production of successful offspring by both themselves and their relatives (Hamilton, 1964), a pro- 
cess that has become known as kin selection. This formulation redirects the unit of conceptual analysis from the individual organism to his or her genes, for it is genes that survive and are passed on and some of the same genes will be found in siblings, nephews and nieces, grandchildren, cousins, etc., as well as offspring. If an animal sacrifices its life for its siblings' offspring, it ensures the survival of common genes, for, on average, it shares $50 \%$ of its genes with each of its siblings and $25 \%$ with these siblings' offspring.

It is predicted, then, that the percentage of genes shared is an important determiner of the amount of altruism displayed, and this is borne out in a number of species. Social ants, for example, are one of the most altruistic species so far discovered. The self-sacrificing, sterile worker and soldier ants do little else than serve their colony. They also, however, share $75 \%$ of their genes with their sisters, so by working for others, and sacrificing their lives if need be, they help to propagate their own genes. A similar extreme form of altruism may occur in clones (e.g., aphids), where individuals are $100 \%$ related. Thus altruism and degree of genetic similarity are closely related.

Kin selection essentially means that genes may ensure their own survival, not only by causing the organism of which they form a part to reproduce, but also by causing it to act in such a way that its relatives reproduce more than they would have done without its action. The idea of kin selection is not new (Hamilton, 1964), but it has only recently become more widely known (Dawkins, 1976; Wilson, 1975) and forms a key element in sociobiological theory. Kin-selection theory, however, can be incorporated into genetic similarity theory.

\section{GENETIC SIMILARITY THEORY}

It seems strange to us that attention has been focused on the particular example of kin selection, for a more general principle is involved. A gene may ensure its own survival by acting so as to bring about the reproduction of any organism in which copies of itself are to be found. This is the crux of what we refer to as genetic similarity theory (GST). Putting it another way, GST states that there is an alternative means by which genes propagate themselves to those usually discussed in sociobiological theorizing. Rather than merely protecting kin at the expense of strangers, organisms have a tendency to detect other genetically similar organisms and to exhibit altruistic behavior toward these "strangers," as well as toward its own relatives. In order to pursue this general strategy, it must, in effect, be able to detect copies of its genes in other organisms. The 
processes by which it does this will require elucidation; the cues will necessarily be phenotypic.

Many aspects of genetic similarity theory have been proposed previously (e.g., Dawkins, 1976, 1982; Hamilton, 1964; Lopreato, 1981; Thiessen and Gregg, 1980; Samuelson, 1983; Rushton, 1984a,b; Russell et al., 1984). Dawkins (1976, 1982), for example, building on Hamilton (1964), suggested a thought experiment in which a gene had two effects: it causes individuals possessing it to have a green beard and to behave altruistically toward green-bearded individuals. The green beard serves as a recognition cue for the altruistic gene. Altruism therefore can occur with no necessity for the individuals concerned to be related. Similarly, Thiessen and Gregg (1980) theorized that, "The flow of altruistic behaviors, the ease of information transfer, and the genetic benefits of positive assortative mating are linked to the degree to which interacting individuals share homologous genes (p. 111)." They extensively reviewed data from both animals and humans to support their contention that, "Friends of either sex, as well as mates, resemble each other in many ways, suggesting that genetic assortment operates at all levels of social affiliation (p. 117)." Finally, Samuelson (1983) provided mathematical models demonstrating that altruism, kin selection, and "like-gene selection" could occur under natural selection.

Sociobiologists have also offered an alternative mechanism by which altruism may evolve. This is reciprocal altruism. Here there is no necessity for genetic relatedness. All that is posited is that performance of an altruistic act will result in a return of altruistic behavior (Trivers, 1971). Genetic similarity theory interacts with the theory of the natural selection of reciprocal altruism and predicts that the more genes shared by organisms, the easier reciprocal altruism and cooperation will develop. There would be no necessity for strict reciprocity. Thiessen and Gregg (1980) made the same point: "cooperation among 'nonrelatives' ('reciprocal altruism') may be based in large part on genetic and phenotypic similarity (p. 133)."

In the following sections several data sets are ordered within the context of genetic similarity theory. These include (a) kin recognition studies of animals raised apart, (b) assortative mating, (c) intrafamilial relations, (d) human friendship and altruism, and (e) ethnic nepotism. Finally, we discuss a strong and a weak version of GST and offer some predictions for future research.

\section{KIN RECOGNITION STUDIES IN ANIMALS RAISED APART}

A number of studies have recently appeared concerned with kin recognition in animals raised apart. In one, Greenberg (1979) provided a 
striking demonstration of the ability of the sweat bee, Lasioglossum zephyrum, to discriminate between conspecifics of varying degrees of relatedness even though they have not previously met. Guard bees of this species can effectively block the nest to prevent an intruder entering. In this study bees were first bred for 14 different degrees of genealogical relationship with each other. Then they were introduced near nests that contained either sisters, aunts, nieces, first cousins, or more distantly related bees. The guard in each case was expected to make a binary decision-either permitting the introduced bee to pass or actively preventing it from doing so. The results demonstrated a strong linear relationship $(r=0.93)$ between being able to pass the guard bee and the degree of genetic relatedness. In other words, the greater the degree of genetic similarity, the greater the proportion of bees that were allowed to enter the hive. Thus the guard bees appear to be able to detect the degree of genetic similarity between themselves and the intruder. In subsequent kin recognition studies of the honey bee, Apis mellifera (Breed, 1983; Getz and Smith, 1983), a genetic base to the behavior is suggested by the discrimination shown between full and half-sisters raised in neighboring cells.

There is also evidence that the ability to detect genetic similarity exists in species such as tadpoles, birds, deermice, ground squirrels, and macaques. Consider the studies carried out on tadpoles of the frog Rana cascadae (Blaustein and O'Hara, 1981, 1982). Typically, the tadpoles are separated before hatching and reared in isolation. Subsequently the individual tadpoles are placed in a rectangular tank with two end compartments created by plastic mesh. Siblings are placed in one end compartment and nonsiblings are placed in the other. The results showed that the tadpoles spend more time at the sibling end of the tank than at the other. Because the tadpoles were separated as embryos and raised in complete isolation, a genetic similarity detection ability is implicated. Similar findings have been reported for tadpoles of the toad Bufo americanus (Waldman, 1982).

Kin recognition has been reported for avian species by Bateson (1978, 1982), using Japanese quail, and by Radesater (1976), using Canada geese. Bateson (1982) found that quail reared with siblings and tested with unknown individuals of the opposite sex preferred first to third cousins and both of these to unrelated conspecifics. In mammals, sibling recognition has been reported for three species of ground squirrel (Davis, 1982; Holmes and Sherman, 1982), for spiny mice (Porter and Wyrick, 1979), and for deermice (Grau, 1982). A study on pigtail macaques, Macaca nemestrina, by Wu et al. (1980), found that more interest was shown in paternal half-siblings than in nonrelatives by individuals who had been 
separated from their mothers 5 min after birth, raised in incubators, and then reared with totally unrelated peers. Interest was measured by the amount of time the animals spent interacting with each other in an apparatus containing several compartments. Because the half-siblings were paternally related, common prenatal experience cannot explain the preferences.

\section{ASSORTATIVE MATING}

A well-known phenomenon which is readily explained by GST is that of assortative mating. It could be argued that assortative mating has nothing to do with genetic similarity but occurs as a result of common environmental influences. This argument has difficulty accounting for the incidence of assortative mating in species ranging from insects through birds to primates in laboratory as well as natural settings (Thiessen and Gregg, 1980). Moreover, that assortative mating in animals is based on genetic similarity is suggested by a group of experiments showing that individuals can detect known chromosomal differences in conspecifics. For example, Nevo and Heth (1976) reported that estrous females of the mole rat Spalax ehrenbergi, given a choice between males of two chromosomal forms, significantly preferred a male of their own chromosomal form. Similarly, Stalker (1976) found evidence for strong assortative mating for certain chromosomal inversions and their associated phenotypes in studies on wild populations of Drosophila melanogaster.

As far as humans are concerned, it is widely accepted that assortative mating occurs on the basis of such characteristics as race, socioeconomic status, physical attractiveness, ethnic background, religion, social and political attitudes, level of education, and IQ (Thiessen and Gregg, 1980; Vandenberg, 1972). The median assortative mating coefficient for IQ, for example, averaged over 16 studies involving 3817 pairings, is 0.37 (Bouchard and McGue, 1981). Although the coefficients are lower than for IQ, there is also assortative mating for personality traits, values, and vocational interests, many studies of which demonstrate some $50 \%$ of the variance to be associated with genetic influence (Rushton, 1984a). Assortative mating is also found for a variety of abnormal traits, including criminality, alcoholism, the affective disorders, and schizophrenia. Assortative mating coefficients also are present for a very wide range of anthropometric features, family size, and longevity (Thiessen and Gregg, 1980). While most assortative mating coefficients are extremely small in magnitude, nonetheless, it is consistently found that significantly more are positive than negative. While each dimension adds only a fractional 
amount to the total genetic variance shared by spouses, the cumulative effects, of course, may be considerable.

One recent study examined cross-racial marriages in Hawaii and found that there was more similarity in personality test scores among males and females who married across ethnic groups than among those marrying within (Ahern et al., 1981). The authors posit that, given the general tendency toward homogamy, cross-racial/ethnic couples marrying heterogamously on this dimension tend to "make up" for this dissimilarity by choosing spouses more similar to themselves in other domains than do persons marrying within their own racial/ethnic group.

Several studies have suggested that the degree of assortative mating, in both animal and human studies, is correlated with fecundity. Positive relations between number of children and similarity of spouses have been found in humans, for example, for similarity on anthropometric variables, intelligence test scores, educational attainment, and family size (see Thiessen and Gregg, 1980, for a review). The upper limit on the fitnessenhancing character of assortative mating occurs, of course, with incest. Too much genetic similarity between mates increases the chances that harmful recessive genes may combine. The negative effects of "inbreeding depression" have been demonstrated in many species, including humans (Thiessen and Gregg, 1980; van den Berghe, 1983). As a result it has been hypothesized that there is a genetic basis to the "incest taboo" through a number of proximal mechanisms, including (1) negative imprinting on intimate associates at an early age, (2) dispersal, and (3) inhibition of estrous in the presence of close male relatives (van den Berghe, 1983). Optimal fitness, then, consists in selecting a mate who is genetically similar but not actually a relative. It would be of interest to quantify the ideal percentage; van den Berghe (1983) speculates that it is about $12.5 \%$, or the same as that between first cousins.

\section{FAMILY RELATIONSHIPS}

It would appear from the previous section that humans assortatively mate on a wide variety of characteristics including both personality and physical qualities. Given that many of the dimensions are partly inherited, it means that spouses are genetically more similar to each other than they are to an average person. According to GST this means that there will be altruism between spouses. This has important implications for family life. Several studies have shown that not only the occurrence but also the stability of relationships can be predicted by the degree of matching on personality characteristics (Bentler and Newcomb, 1978; Cattell and 
Nesselroade, 1967; Hill et al., 1976; Meyer and Pepper, 1977; Terman and Buttenwieser, 1935a,b).

A related expectation involves parental care of their offspring as a function of the degree of genetic similarity between spouses. A general prediction is that the more genetically similar the parents are to each other, the more genetically similar they and their children will be to each other, and the more within-family altruism will occur. Conversely, the less genetically similar the parents are to each other, the less genetically similar they and their children will be to each other, and the less withinfamily altruism will occur. This proposition could be tested in at least two ways: parents who are first cousins may be more protective toward their children than less related parents; and in multiethnic countries, the greater the disparity in ethnicity between parents (and, presumably, on average, the lower the genetic similarity), the less protectiveness and care for the children there will be.

A different test of GST could be made by examining preferences within families. Although each parent will have a minimum of $50 \%$ of his or her genes in common with each offspring, upward variations on this percentage will be expected. Some children will be genetically more similar to one parent than the other. This can readily be demonstrated in the hypothetical case in which two parents share $10 \%$ of their genes in common. Suppose that the father gives the child $50 \%$ of his genes, $2 \%$ of which are shared with the mother, and the mother gives the child $50 \%$ of her genes, $8 \%$ of which are shared with the father. If this occurred, the child would share $52 \%$ of his genes with the mother $(50 \%$ from mother, $2 \%$ from father) and $58 \%$ of his genes with the father (50\% from father, $8 \%$ from mother). By analogous reasoning, it is expected that while siblings, on average will be $50 \%$ genetically similar to each other, fluctuations around this figure will occur. Parents and siblings can be expected to favor the child who is most similar to them. Favoritism within families is an unexplored topic. GST may render it an important one.

Evidence in favor of the GST predictions for differential within-family altruism comes from studies of rhesus monkeys growing up in large, captive, outdoor-living, multimale, multifemale, social troops in which adults of both sexes are promiscuous. Suomi (1982) cited studies in which rhesus mothers reacted differently to their infant being touched, depending on the interloper's degree of relatedness to their offspring: paternal half-siblings were chased away less often than were unrelated juveniles. This suggests that mothers were able to discriminate the degree of similarity among their own offspring, paternal half-siblings to their offspring, and individuals unrelated to them. There is also evidence that males "recognize" their own offspring, for Suomi (1982) reported that, despite 
male and female promiscuity, males proferred preferential treatment to their own offspring compared to nonoffspring. In the above examples, the degree of genetic relatedness was established by blood tests. Suomi (1982) also reported ongoing research in which it was predicted that full siblings would interact more frequently with each other than they would with half-siblings, who, in turn, would interact more frequently with each other than they would with nonrelated peers. The results should provide useful tests of GST in these nonhuman primates.

In the case of humans, children dissimilar to a parent are at risk. A disproportionate number of battered babies are stepchildren (Lightcap et al., 1982). Adoptions are more likely to be successful when the parents perceive the child as similar to them (Jaffee and Fanshel, 1970). Finally, anthropological data show that when paternity is uncertain (that is, when there is a considerable risk of low genetic similarity between a man and his wife's children), extreme measures may be taken: more resources may be invested in a sister's than a wife's children; in 15 of 60 societies studied, adultery constitutes grounds for infanticide (Daly and Wilson, 1981).

\section{A GENETIC BASIS TO FRIENDSHIP}

GST may also have predictive power where relationships outside the family are concerned, especially since friendships appear to be formed on the basis of similarity. This holds for similarity as perceived by the friends (La Gaipa, 1977). It also holds for similarity on a variety of measured characteristics. For example, Berkowitz (1969) found that friends tend to be of similar height. It has been more usual to assess similarity by questionnaire. Using such methods, friendship or liking has been linked to similarity of activities, needs, personal constructs, attitudes, and personality (Berscheid and Walster, 1978).

In the experimental literature on the social psychology of liking, one of the most powerful manipulations possible is perceived similarity. Experimentally manipulated apparent similarity of personality, attitudes, or any of a wide range of beliefs has been found to be positively related to liking in subjects of varying ages and from many different cultures (Berscheid and Walster, 1978). In short, as far as the friendship literature is concerned, as earlier in the assortative mating literature, it is primarily similarity theory rather than the opposite, complementary theory, that is congruent with the data. Genetic similarity theory predicts a genetic basis to friendship and that liking is one of the mechanisms which leads to altruism. Certainly in young children it has been demonstrated that friend- 
ship sociograms correspond closely to sociograms based on altruism patterns (Strayer et al., 1979).

Much human altruism and friendship is reciprocal in nature. On the basis of comparative anthropological data, Mauss (1954) concluded that three types of obligations are widely distributed in human societies in both space and time: (a) the obligation to give, (b) the obligation to receive, and (c) the obligation to repay. Reciprocal exchanges breed cooperation and good feelings. A failure (or inability) to reciprocate, on the other hand, breeds bitterness and dislike. Numerous studies have demonstrated the tendency of individuals to reciprocate favors (Rushton, 1980). The tendency appears to be there among preschoolers (Strayer et al., 1979). Genetic similarity theory predicts reciprocal altruism arises more frequently among genetically similar others than among those genetically dissimilar.

We have implied that genetic similarity leads to liking, that liking leads to friendship, and that friendship facilitates altruism. The most direct test of the validity of GST in this context is to see if genetic similarity produces altruism. We know of no appropriate direct test. However, it is possible to ask whether or not altruism is generally increased by actual or perceived similarity. Stotland (1969) reported studies in which subjects observed another person apparently receiving electric shocks. By manipulating the subjects' beliefs about similarity to the confederate, Stotland demonstrated appropriate covariations between this and physiological reactions and reported empathy. Subsequently, Krebs (1975) found that apparent similarity increased not only physiological measures indicating empathy but also willingness to reward the victim.

\section{ETHNIC NEPOTISM}

We wish to touch only briefly on the notion of ethnicity. Obviously, however, the very notion of ethnicity is based on the idea of extended kinship. Two individuals within an ethnic group will, on average, be more genetically similar than two from different ethnic groups. The implications of this for relations between ethnic groups may be far reaching. There will be, for example, a biological basis for what van den Berghe (1981) has characterized as "ethnic nepotism." Ethnic nepotism is manifest in many ways. It explains why group members often prefer to congregate in the same geographical area. Ethnic nepotism also predicts clear patterns of altruism - charitable donations, for example, are predicted to be made in greater quantities within ethnic groups than between them. Many studies have found that people are more likely to help members of their 
own race or country than members of other races or foreigners (Brigham and Richardson, 1979; Feldman, 1968).

\section{GST: THE STRONG AND WEAK VERSIONS}

So far, we have been concerned with demonstrating the possibility that humans and other species possess the ability to detect genetic similarity in others and to respond differentially to them on this basis. It is now appropriate to make explicit the ways in which this ability could arise. The strong version of the theory implies that individuals possess the ability to recognize genetic similarity in the absence of previous familiarity or other proximal mechanisms (Dawkins's 1976 "greenbeard effect"). Thus, some phenotypes are inherently more attractive to the organism than are others. Several of the animal studies previously cited are congruent with this possibility.

If a strong version of GST is correct, it follows that similarity based on genetic traits would predict altruism more than similarity based on nongenetic causes. This deduction could be tested in the context of friendship, for while most sociobiological theorizing would expect people to report that their intention would be to help close kin over distant kin and distant kin over strangers, GST predicts that friends may be responded to with at least as much altruism as distant kin and that the greater the genetic similarity between friends, the more altruism would be expected. To test this prediction estimates of genetic similarity among friends and relatives are needed. Biological techniques such as chromosome analysis would be ideal, while blood antigen analysis may provide a reasonable approximation. Cruder estimates are also possible. For example, similarity on major polygenic traits known to have high heritabilities should be more predictive of friends' altruism than similarity on equivalent traits of lower heritability. Unfortunately, the differential heritability of personality traits is by no means established, nor can one estimate the relative number of genes contributing to each trait. However, it may be possible to construct two alternative forms of questionnaire measures of the same personality trait, one composed of items of high heritability and the other of items of low heritability.

The weak version of GST implies that the ability to detect genetic similarity is acquired through a process of exposure to appropriate stimuli. Again, there is evidence that this mechanism may also operate. For example, Zajonc (1980) has experimentally demonstrated that the more familiar a variety of stimuli is (across a range of species, including humans), the greater the preference shown. Bateson (1978) and van den Berghe (1983) have suggested that sexual preferences may be established 
early in life by means of an imprinting-like process. Thus, as Dawkins (1982) and Kareem (1983) discuss, the kin recognition studies we cited earlier need not be interpreted as "innate" or genetic. With unfamiliar siblings it may be achieved by familiarity with the individual's own odor or that of a close relative (Dawkins's 1982 "armpit effect"); individuals that smell as self could be distinguished from those that smell differently. Porter and Moore (1981) have demonstrated that bodily odors may also be salient stimuli for kin recognition among humans. They found that $T$ shirts worn by individual children were correctly identified by the siblings and mothers of those children through olfactory cues alone. Furthermore, parents correctly distinguished between the odors of otherwise identical shirts worn by two of their own children.

It is possible to envisage situations in which the genetic similarity detection mechanisms could be deceived, especially when they are customarily established by imprinting and learning processes. Redican and Kaplan (1978) applied synthetic odors to female squirrel monkeys and found that the social preferences of their infants, as measured by a series of visual discrimination tests, were affected over the first few months of life. Furthermore, preferences for the familiar synthetic rearing odor over an unfamiliar synthetic odor were demonstrated in month 5 postpartum. Finally, Kareem and Barnard (1982), in a study on mice, and O'Hara and Blaustein (1982), in a study on tadpoles, found that previously established kinship interaction preferences disappeared when other animals were allowed to become familiar. Proximal mechanisms which increase fitness under one set of ecological circumstances may, of course, reduce fitness under a different set.

We can at present only speculate on the extent to which these differing processes may operate in humans. Both the strong and the weak versions of GST necessarily involve phenotypic cues; how these mediate behavior, however, requires investigation. It should, in any case, be emphasized that we do not necessarily regard the two versions as mutually exclusive. Since there are evolutionary advantages to be derived from the ability to detect genetic similarity, it may well be the case that both distal and proximal mechanisms are employed.

\section{CONCLUSION}

We have reviewed evidence to the effect that individuals are able to detect genetic similarity in others and respond accordingly. GST is, in our view, capable of providing an extension to certain aspects of evolutionary theory and its applications to human behavior. It need not, of course, be confined to those areas of psychology which we have chosen 
to discuss; the theory also has considerable implications for the study of social behavior in small groups and even within and between nations. Much of the evidence we have cited could be explained in a variety of different ways. The idea of GST does not necessarily conflict with these alternative explanations but appears to be one of the few theories which is currently capable of providing a parsimonious explanation of a whole range of disparate findings.

\section{ACKNOWLEDGMENTS}

This article is based on a symposium presented at the 13th Annual Meeting of the Behavior Genetics Association, London, England, July 5-8, 1983. We thank T. J. Bouchard Jr., H. J. Eysenck, D. W. Fulker, M. A. Goodale, C. H. Littlefield, and N. G. Martin for discussions and J. H. Bruell for editorial comments.

\section{REFERENCES}

Ahern, F. M., Cole, R. E., Johnson, R. C., and Wong, B. (1981). Personality attributes of males and females marrying within vs. across racial/ethnic groups. Behav. Genet. 11:181-194.

Bateson, P. P. G. (1978). Sexual imprinting and optimal outbreeding. Nature 273:659-660.

Bateson, P. P. G. (1982). Preference for cousins in Japanese quail. Nature 295:236-237.

Bentler, P. M., and Newcomb, M. D. (1978). Longitudinal study of marital success and failure. J. Consult. Clin. Psychol. 40:1053-1070.

Berkowitz, W. R. (1969). Perceived height, personality, and friendship choice. Psychol. Rep. 24:373-374.

Berscheid, E. and Walster, E. (1978). Interpersonal Attraction, 2nd ed., Addison-Wesley, Reading, Mass.

Blaustein, A. R., and O'Hara, R. K. (1981). Genetic control for sibling recognition? Nature 290:246-248.

Blaustein, A. R., and O'Hara, R. K. (1982). Kin recognition in Rana cascadae tadpoles: Maternal and paternal effects. Anim. Behav. 30:1151-1157.

Bouchard, T. J., Jr., and McGue, M. (1981). Familial studies of intelligence: A review. Science 212:1055-1059.

Breed, M. D. (1983). Nestmate recognition in honey bees. Anim. Behav. 31:86-91.

Brigham, J. C., and Richardson, C. B. (1979). Race, sex and helping in the marketplace. J. Appl. Soc. Psychol. 9:314-322.

Cattell, R. B., and Nesselroade, J. R. (1967). Likeness and completeness theories examined by Sixteen Personality Factor measures on stably and unstably married couples. $J$. Personal. Soc. Psychol. 7:351-361.

Daly, M., and Wilson, M. I. (1981). Child maltreatment from a sociobiological perspective. New Direct. Child Dev. 11:93-112.

Davis, L. S. (1982). Sibling recognition in Richardson's ground squirrels (Spermophilus richardsonii). Behav. Ecol. Sociobiol. 11:65-70.

Dawkins, R. (1976). The Selfish Gene, Oxford University Press, Oxford.

Dawkins, R. (1982). The Extended Phenotype, Freeman, San Francisco, Calif.

Feldman, R. E. (1968). Response to compatriot and foreigners who seek assistance. $J$. Personal. Soc. Psychol. 10:202-214.

Getz, W. M., and Smith, K. B. (1983). Genetic kin recognition: Honey bees discriminate between full and half sisters. Nature 302:147-148. 
Grau, H. J. (1982). Kin recognition in white-footed deermice (Peromyscus leucopus). Anim. Behav. 30:497-505.

Greenberg, L. (1979). Genetic component of bee odor in kin recognition. Science 206:10951097.

Hamilton, W. D. (1964). The genetical evolution of social behavior: I and II. J. Theor. Biol. $7: 1-52$.

Hill, C. T., Rubin, Z., and Peplau, L. A. (1976). Breakups before marriage: The end of 103 affairs. J. Soc. Issues 32:147-168.

Holmes, W. G., and Sherman, P. W. (1982). The ontogeny of kin recognition in two species of ground squirrels. Am. Zool. 22:491-517.

Jaffee, B., and Fanshel, D. (1970). How They Fared in Adoption: A Follow-Up Study, Columbia, New York.

Kareem, A. M. (1983). Effect of increasing periods of familiarity on social interactions between male sibling mice. Anim. Behav. 31:919-926.

Kareem, A. M., and Barnard, C. J. (1982). The importance of kinship and familiarity in social interactions between mice. Anim. Behav. 30:594-601.

Krebs, D. L. (1975). Empathy and altruism. J. Personal. Soc. Psychol. 32:1134-1146.

La Gaipa, J. J. (1977). Testing a multidimensional approach to friendship. In Duck, S. (ed.), Theory and Practice in Interpersonal Attraction, Academic Press, London.

Lightcap, J. L., Kurland, J. A., and Burgess, R. L. (1982). Child abuse: A test of some predictions from evolutionary theory. Ethol. Sociobiol. 3:61-67.

Lopreato, J. (1981). Toward a theory of genuine altruism in Homo sapiens. Ethol. Sociobiol. $2: 113-126$.

Mauss, M. (1954). The Gift: Forms and Function of Exchange in Archaic Societies, Free Press, Glencoe, III.

Meyer, J. P., and Pepper, S. (1977). Need compatibility and marital adjustment in young married couples. J. Personal. Soc. Psychol. 35:331-342.

Nevo, E., and Heth, G. (1976). Assortative mating between chromosome forms of the mole rat, Spalax ehrenbergi. Experientia 32:1509-1511.

O'Hara, R. K., and Blaustein, A. R. (1982). Kin preference behavior in Bufo boreas tadpoles. Behav. Ecol. Sociobiol 11:43-49.

Porter, R. H., and Moore, J. D. (1981). Human kin recognition by olfactory cues. Physiol. Behav. 27:493-495.

Porter, R. H., and Wyrick, M. (1979). Sibling recognition in spiny mice (Acomys cahirinus): Influence of age and isolation. Anim. Behav. 27:761-766.

Radesater, T. (1976). Individual sibling recognition in juvenile Canada geese (Brant canadensis). Can. J. Zool. 54:1069-1072.

Redican, W. K., and Kaplan, J. N. (1978). Effects of synthetic odors on filial attachment in infant squirrel monkeys. Physiol. Behav. 20:79-85.

Rushton, J. P. (1980). Altruism, Socialization, and Society, Prentice-Hall, Englewood Cliffs, N.J.

Rushton, J. P. (1984a). Sociobiology: Towards a theory of individual and group differences in personality and social behavior. In Royce, J. R., and Mos, L. P. (eds.), Annals of Theoretical Psychology, Vol. 2, Plenum Press, New York.

Rushton, J. P. (1984b). Group differences, genetic similarity theory, and the importance of personality traits. In Royce, J. R., and Mos, L. P. (eds.), Annals of Theoretical Psychology, Vol. 2, Plenum Press, New York.

Rushton, J. P., and Sorrentino, R. M. (eds.) (1981). Altruism and Helping Behavior: Social, Personality, and Developmental Perspectives, Lawrence Erlbaum Associates, Hillsdale, N.J.

Rushton, J. P., Fulker, D. W., Neale, M. C., Blizard, R. A., and Eysenck, H. J. (1984). Altruism and genetics. Acta Genet. Med. Gemellol. (in press).

Russell, R. J. H., Rushton, J. P., and Wells, P. A. (1984). Sociobiology, personality and genetic similarity detection. In Royce, J. R., and Mos, L. P. (eds.), Annals of Theoretical Psychology, Vol. 2, Plenum Press, New York. 
Samuelson, P. A. (1983). Complete genetic models for altruism, kin selection and like-gene selection. J. Soc. Biol. Struct. 6:3-15.

Stalker, H. D. (1976). Chromosome studies in wild populations of D. melanogaster. Genetics, 82:323-347.

Stotland, E. (1969). Exploratory investigations of empathy. In Berkowitz, L. (ed.), Advances in Experimental Social Psychology, Vol. 4, Academic Press, New York.

Strayer, F. F., Wareing, S., and Rushton, J. P. (1979). Social constraints on naturally occurring preschool altruism. Ethol. Sociobiol. 1:3-11.

Suomi, S. J. (1982). In Lamb, M. E., and Sutton-Smith, B. (eds.), Sibling relationships, in nonhuman primates, Erlbaum, Hillsdale, N. J.

Terman, L. M., and Buttenwieser, P. (1935a). Personality factors in marital compatibility. I. J. Soc. Psychol. 6:143-171.

Terman, L. M., and Buttenwieser, P. (1935b). Personality factors in marital compatibility. II. J. Soc. Psychol. 6:267-289.

Thiessen, D. D., and Gregg, B. (1980). Human assortative mating and genetic equilibrium: An evolutionary perspective. Ethol. Sociobiol. 1:111-140.

Trivers, R. L. (1971). The evolution of reciprocal altruism. Q. Rev. Biol. 46:35-57.

Vandenberg, S. G. (1972). Assortative mating, or who marries whom? Behav. Genet. 2:127157.

van den Berghe, P. L. (1981). The Ethnic Phenomenon, Elsevier, New York.

van den Berghe, P. L. (1983). Human inbreeding avoidance: Culture in nature. Behav. Brain Sci. 6:91-123.

Waldman, B. (1982). Sibling association among schooling toad tadpoles: Field evidence and implications Anim. Behav. 30:700-713.

Wilson, E. O. (1975). Sociobiology: The New Synthesis, Harvard University Press, Cambridge, Mass.

Wu, H. M. H., Holmes, W. G., Medina, S. R., and Sackett, G. P. (1980). Kin preference in infant Macaca nemestrina. Nature 285:225-227.

Zajonc, R. B. (1980). Feeling and thinking. Preferences need no inferences. Am. Psychol. 35:151-175.

Edited by Jan H. Bruell 